\title{
Effective Temperature Distribution and Drawing Speed Control for Stable Dieless Drawing Process of Metal Tubes*
}

\author{
Tsuyoshi FURUSHIMA* ${ }^{* *}$, Syuhei HIROSE ${ }^{* *}$ and Ken-ichi MANABE** \\ **Department of Mechanical Engineering, Tokyo Metropolitan University, \\ 1-1 Minami-ohsawa, Hachioji, Tokyo, 192-0397, Japan \\ E-mail: furushima-tsuyoshi@tmu.ac.jp
}

\begin{abstract}
Dieless drawing technique, which can achieve a large reduction in the area of metal tubes in a single pass by local heating and cooling, is a flexible metal drawing process without dies. In this study, we suggested the effective drawing path control in the early drawing stage to restrain the unstable deformation, which leads to fracture. The actual deformation limit of the material is evaluated by coupled thermo-mechanical finite element analysis and experiments of the dieless drawing. The metal tubular materials used in the experiment are SUS304 alloy tubes of $2 \mathrm{~mm}$ outer diameter. A high-frequency induction heating apparatus with a water-cooling box is used for the dieless drawing. Results show that effective drawing speed control enhances the forming limit in the dieless drawing. Moreover, the effect of heating length, which affects the temperature distribution, on the deformation behavior is investigated in the use of effective drawing speed control under the condition of avoiding the fracture by unstable deformation in the early drawing stage. It is found that the forming limit slightly improves with increasing heating length. Consequently, we clarified that it is possible to make the dieless drawing process successfully even if the local heating is not always realized.
\end{abstract}

Key words: Dieless Drawing, Temperature Distribution, Speed Control, Metal Tube

\section{Introduction}

The dieless drawing by the use of local heating and cooling devices of metal wires, bars and tubes is to replace the conventional die drawing. This technique can achieve a great reduction of materials in a single pass by the local heating and cooling approach compared with conventional die drawing. The flow stress of materials is reduced significantly and the ductility is enhanced considerably at elevated temperature. At local heated part, the necking occurs and diffuses out with moving of heating and cooling devices. The dieless drawing has the advantages of a non-contact, and flexible metal forming process without the use of conventional dies. The dieless drawing has remarkable advantages over the conventional die drawing technique not only improving the drawability, but also eliminating the use of expensive dies and lubricants.

The idea of dieless drawing technique was introduced by Weiss et al. ${ }^{(1)}$. They applied the dieless drawing to steels and Ti alloy rods, and achieved a reduction in area of $50 \%$. Alexsander et al. used SUS304 and Ti alloy rods and bars in the dieless drawing ${ }^{(2)}$. Sekiguchi et al. investigated the dieless drawabilities of carbon steels and SUS304, pure titaniums ${ }^{(3)}$. They successfully formed tapered rods, various cross-sections bars, circular

*Received 1 Sep., 2008 (No. 08-0637) [DOI: 10.1299/jmmp.3.236] 
tubes and clad wire rods by using the flexibility of dieless drawing. Meanwhile, Carolan and Eynatten indicated that a wide variety of microstructures and mechanical properties were obtained using different dieless drawing strategies ${ }^{(4,5)}$. In addition, the authors applied the dieless drawing to superplastic metal tubes for the fabrication of microtubes ${ }^{(6,7)}$. Thus, the dieless drawing technique has wide applications.

In general, the forming limit in dieless drawing process depends on the difference in the flow stress between the heated and cooled areas on the basis of basic equilibrium equation (8). The relationship between the theoretical limiting reduction in area $r_{c}$, and the flow stresses at heated and cooled parts $\sigma_{h}$ and $\sigma_{c}$, respectively, can be expressed as

$$
r_{c}=1-\sigma_{h} / \sigma_{c}
$$

According to their reports, the theoretical forming limits obtained from Eq. (1) were modestly in good agreement with experimental results for the various materials used. However, Eq. (1) was derived under steady state condition in dieless drawing. Actually, the deformation in the steady state differs from the deformation in the nonsteady state in the early dieleses drawing stage. The previous reports indicate that fracture occurs at the nonsteady state in early drawing stage ${ }^{(1) \sim(3)}$. The authors also show experimentally and numerically that the unstable deformation that occurs in the early drawing stage leads to fracture $^{(6,7,9)}$. In fact, the fracture risk of the unstable deformation was underrepresented compared with the actual forming limit of the materials, as shown in Eq. (1). However, no research was conducted to focus on this difference at all. Previous reports on dieless drawing did not differentiate between the fracture caused by unstable deformation in the early drawing stage and the forming limit based on the difference in the flow stress of materials between the heated and cooled parts.

Moreover, it is known that an important factor for the forming limit is temperature distribution. Many researchers indicated that local heating is essential in dieless drawing, because the necking in the early drawing stage did not stop and led to fracture if local heating is not enough ${ }^{(1) \sim(3)}$. However the deformation behavior in the non-steady state was investigated in these studies. Thus, if the deformation behavior in the dieless drawing moves into the steady state from the nonsteady state, the forming limit is just dependent on the difference in the flow stress based on the difference in the temperature, as shown in Eq. (1). Therefore, whether local heating will be necessary in dieless drawing is not related to the forming limit. Analytical and numerical approaches of dieless drawing showed the effect of temperature distribution ${ }^{(10) \sim(15)}$. However, these analyses were conducted under steady state condition, and the deformation was not considered under the nonsteady condition. As described above, the fracture occurs most commonly in the nonsteady state in the early dieless drawing stage. In fact, the previous reports did not also differentiate between the fracture caused by unstable deformation in the early drawing stage and the forming limit based on the difference in the flow stress of materials between heated and cooled parts in terms of the importance of local heating. Therefore, the effect of temperature distribution on the deformation behavior and forming limit was not investigated appropriately, because the fracture occurs before the materials reach their actual forming limit.

In our previous study, we developed a coupled thermo-mechanical finite element analysis considering the nonsteady state in dieless drawing, and verified the validity of this analysis ${ }^{(7),(9),(16)}$. In this study, we suggested the new method for controlling the drawing speed to restrain the unstable deformation at the nonsteady state during the dieless drawing. By using this method, the forming limit of the metal tube used was evaluated appropriately under unaffected condition of the unstable deformation that occurred in the early drawing stage. Furthermore, the effect of the temperature distribution on the deformation behavior and the forming limit was investigated under the effective drawing speed control condition, 
and the necessity of local heating during dieless drawing was discussed.

\section{Experiment}

\subsection{Experimental procedure}

The materials used in the experiments were SUS304 stainless steels tubes of $2 \mathrm{~mm}$ outer diameter and $1.4 \mathrm{~mm}$ inner diameter. Figure 1 shows the schematic illustration of dieless drawing for a metal tube. The heating and cooling devices are fixed and the metal tube moves from left to right through the heating zone. Concurrently, the workpiece is subjected to tension by the difference in speed between pulling $V_{1}$ and feeding $V_{2}$. The flow stress of materials is reduced significantly and the ductility is enhanced considerably at elevated temperature. The local temperature increase caused a local plastic deformation. The necking occurred at local heated part and diffuses out with moving heating and cooling devices, achieving a large reduction in area in a single pass drawing. The relationship between the reduction in area $r$ and the speed ratio $V_{2} / V_{1}$ is follows ${ }^{(3)}$.

$$
r=1-V_{2} / V_{1}
$$

Figure 2 show the schematic illustration and photograph of the experimental setup. Two tables with chucks for gripping workpieces can be moved independently at $V_{1}$ and $V_{2}$ by controlling two servomotors with $750 \mathrm{~W}$ power. A high frequency induction heating device with a maximum power of $2 \mathrm{~kW}$ and a frequency of $2.2 \mathrm{MHz}$ was used. The heating coil and the water cooling device were fixed. Two types of heating coil with different heating length $h_{l}=4 \mathrm{~mm}$ and $16 \mathrm{~mm}$ were used to investigate the effect of the temperature distribution on the deformation behavior and forming limit. The stainless steel tubes were heated using the heating coil, which provide a temperature of $1223 \mathrm{~K}$. The dieless drawing experiments were carried out at a feeding speed $V_{2}$ of $5 \mathrm{~mm} / \mathrm{s}$ and reduction in area $r$ of 0 to $40 \%$. Here, the limiting reduction in area obtained from experiments $r_{l}$, defined as the reduction in area $r$ at which the tube fracture occurs, specifies the forming limit. It is measured at a fixed feeding speed $V_{2}$ of $5 \mathrm{~mm} / \mathrm{s}$ while increasing the pulling speed $V_{1}$ by $0.1 \mathrm{~mm} / \mathrm{s}$ until tube fracture occurs.

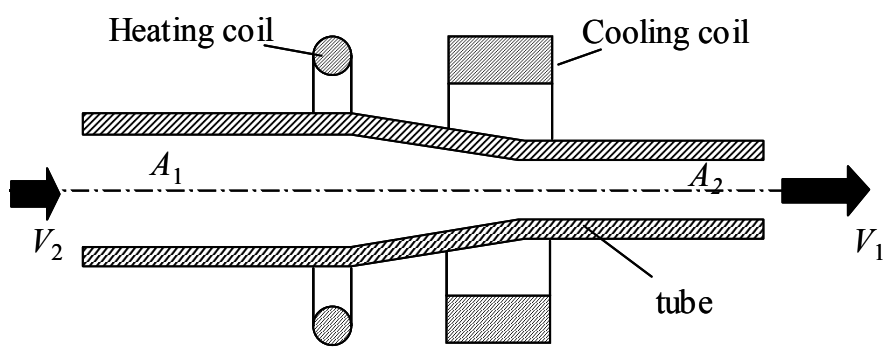

Fig. 1 Schematic illustration of dieless drawing process 


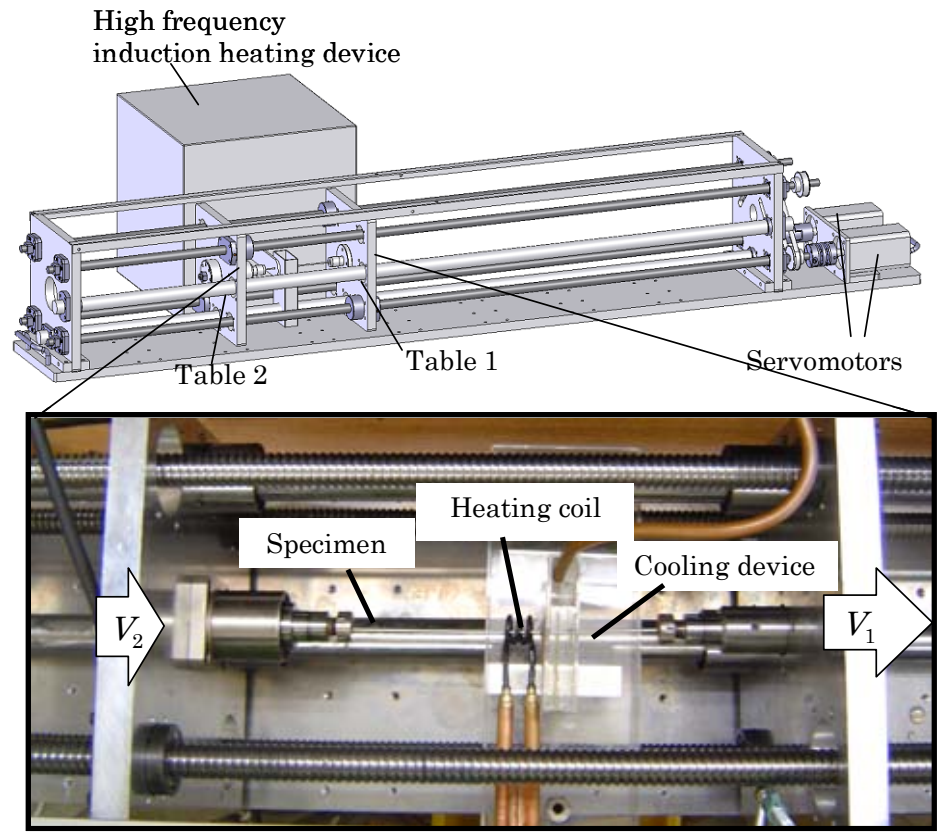

Fig. 2 Schematic illustration and photograph of dieless drawing apparatus used in experiments

\subsection{Drawing speed control path}

The nonsteady state deformation in the early drawing stages causes unstable deformation and fracture ${ }^{(6,9)}$. To restrain the unstable deformation at the nonsteady state, the pulling speed $V_{1}$ was gradually increased from $5 \mathrm{~mm} / \mathrm{s}$, similarly to the feeding speed $V_{2}$ to the target pulling speed $V_{1}$. Figure 3 shows an example of the drawing speed paths used in the experiments. The slope of the pulling speed path from A to B was defined as acceleration $a$.

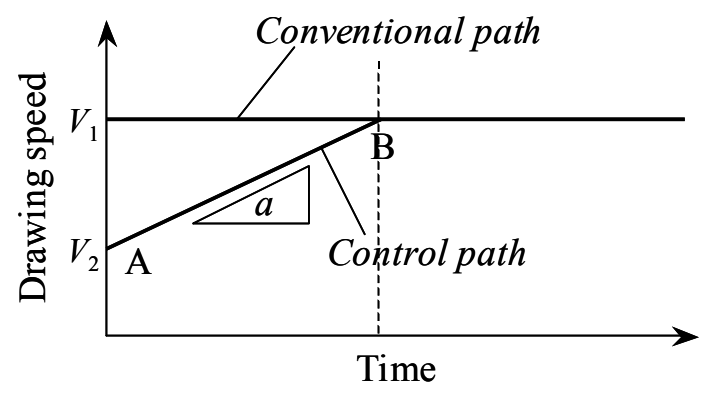

Fig. 3 Example of drawing speed control paths

\section{FE Simulation}

FE simulation by coupled thermo-mechanical analysis was carried out using a commercial FE code MSC MARC/Mentat ver.2005, which considers the heat transfer and deformation of a tube during the dieless drawing process ${ }^{(7,9,16)}$. The FE model used in the dieless drawing is shown in Fig. 4. The tube was modeled using four-node axisymmetric elements. The temperature distribution of a tube during dieless drawing is determined by the amount of heat supplied by the heating coil, heat conductivity of the tubes, heat transfer by the cooling coil, and radiation to the air. In addition, the heating and cooling coils were moved during the dieless drawing. 


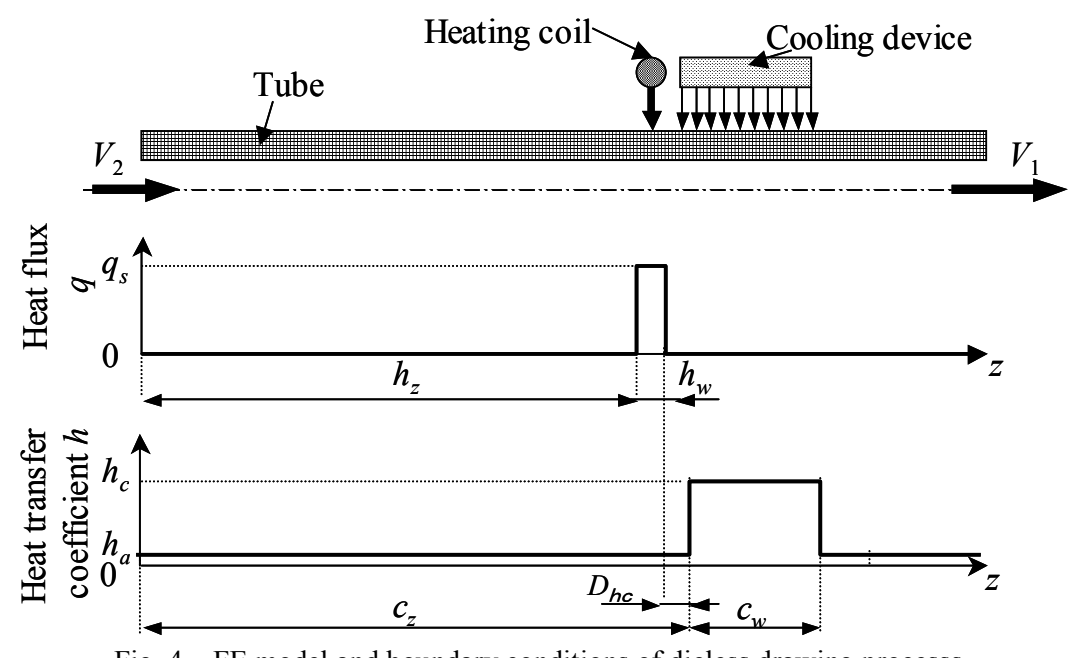

Fig. 4 FE model and boundary conditions of dieless drawing processs

Table 1 Thermal boundary condition used in FE analysis

\begin{tabular}{c|c}
\hline $\begin{array}{c}\text { Heating temperature just beneath the } \\
\text { heating coil } T_{h} / K\end{array}$ & 1223 \\
\hline Heating length $h_{l} / \mathrm{mm}$ & 10 \\
\hline $\begin{array}{c}\text { Heat coefficient of cooling air } \\
h_{c} / \mathrm{W} \cdot \mathrm{mm}^{-2} \cdot \mathrm{K}^{-1}\end{array}$ & 1000 \\
\hline $\begin{array}{c}\text { Heat coefficient of radiation to air } \\
h_{a} / \mathrm{W} \cdot \mathrm{mm}^{-2} \cdot \mathrm{K}^{-1}\end{array}$ & 30 \\
\hline Cooling length $c_{l} / \mathrm{mm}$ & 100 \\
\hline
\end{tabular}

In the present model, the boundary conditions of the heat transfer are shown in Fig. 4. The amount of heat supplied by the heating coil was assumed as the distribution of the heat flux per unit surface area $q_{h}$. The heat flux $q_{h}$ was adjusted such that the temperature just beneath the heating coil was $1223 \mathrm{~K}$. The heat transfers by the cooling coil and radiation to the air were assumed as distributions of the heat transfer coefficient, namely, cooling coil $h_{c}$ and radiation to the air $h_{a}$. In this model, the cooling device was set in an array immediately following the heating coil. In this simulation, the effect of the temperature distribution, which was varied using heating length $h_{l}$, on the deformation behavior was investigated. The thermal boundary conditions are shown in Table 1.

The material used in the simulation is a SUS304 stainless steel, the same as that used in the experiments. A material model that considers the strain hardening and strain rate sensitivity is assumed, and the constitutive equation is expressed as

$$
\sigma=K \varepsilon^{n} \dot{\varepsilon}^{m}
$$

where $\sigma$ is the equivalent flow stress, $K$ is the strength coefficient, $\varepsilon$ is the equivalent strain, $n$ is the strain hardening exponent, $\dot{\varepsilon}$ is the equivalent strain rate, and $m$ is the strain rate sensitivity index. $K(T), n(T)$ and $m(T)$ were assumed as functions of temperature in the following equations in reference to the flow stress curve ${ }^{(17)}$.

$$
\begin{aligned}
& K(T)=0.0007 T^{2}-2.1417 T+1788.3 \\
& n(T)=4.645 \times 10^{-7} T^{2}-3.628 \times 10^{-4} T+4.367 \times 10^{-1} \\
& m(T)=4.374 \times 10^{-5} T+1.449 \times 10^{-3}
\end{aligned}
$$

The material model used is isotropic in the simulation. The thermal coefficients of the 
SUS304 stainless steel used in the simulation are given in Table 2.

The FE simulations were carried out at a feeding speed $V_{2}$ of $5 \mathrm{~mm} / \mathrm{s}$. The limiting reduction in area obtained from the FE analysis, defined as the reduction in area $r$ at which the deformation of the tube locally concentrates and the analysis was stopped, specifies the forming limit. Thus, note that the estimated limiting reduction in area $r_{l}$ obtained from the FE analysis was higher than the actual $r_{l}$. It was measured at a fixed feeding speed $V_{2}$ of $5 \mathrm{~mm} / \mathrm{s}$ while increasing reduction in area $r$ by $5 \%$ until the forming limit.

Table 2 Thermal coefficients of assumed SUS304 stainless steel used in FE analysis

\begin{tabular}{c|c}
\hline Thermal conductivity $/ \mathrm{W} \mathrm{m}^{-1} \mathrm{~K}^{-1}$ & 16.3 \\
\hline Specific heat $/ \mathrm{J} \mathrm{kg}^{-1} \mathrm{~K}^{-1}$ & 502 \\
\hline Mass density $/ \mathrm{g} \mathrm{m}^{-3}$ & 8030 \\
\hline
\end{tabular}

\section{Effective drawing speed control}

\subsection{Unstable deformation}

The reduction in area $r$ was governed by the pulling speed $V_{1}$ and feeding speed $V_{2}$ as shown in Eq. (2). First, the deformation behavior of the tubes with increasing $r$ was investigated to observe the unstable deformation in the early dieless drawing stage under non-drawing speed control condition for heating length $h_{l}=4 \mathrm{~mm}$. Figure 5 shows photographs of the deformation profiles of the tubes drawn at various pulling speeds $V_{1}$. Unstable deformations are observed in the early drawing stages at $r=33.3 \%$ as shown in Figures 5 (c). Actually, the fracture of the tubes occurs because of the unstable deformation in the early drawing stages. As a result, the unstable deformation occurs with increasing reduction in area $r$. The limiting reduction in area was 33.3\%, and the tubes were fractured at greater reductions in area in the experiment under non-drawing speed control condition.

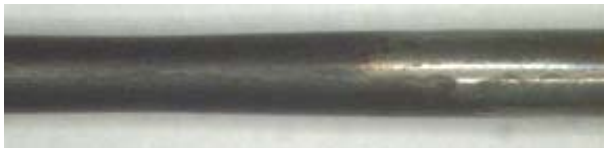

(a) $r=20 \%$

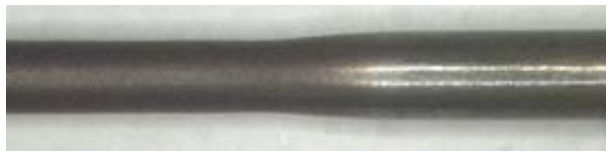

(b) $r=30 \%$
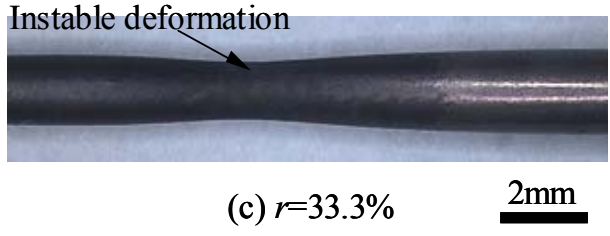

Fig. 5 Effect of reduction in area on deformation behavior $\left(V_{2}=5 \mathrm{~mm} / \mathrm{s}, a=20 \mathrm{~mm} / \mathrm{s}^{2}, T_{h}=1223 \mathrm{~K}\right)$

\subsection{Effect of drawing speed path}

To verify the validity of the drawing speed control in the early drawing stage to restrain the unstable deformation in dieless drawing, the effect of the drawing speed path on the deformation behavior was investigated by FE analysis. The FE simulation was performed under the acceleration of drawing speed $a$ from 2 to $200 \mathrm{~mm} / \mathrm{s}^{2}$ and the pulling drawing speed paths as shown in Fig. 6. Figure 7 shows the drawn tubes obtained from 
FE simulation under the feeding speed $V_{2}=5 \mathrm{~mm} / \mathrm{s}$, and reduction in area $r=55 \%$. For the acceleration of drawing speed $a=20$ and $200 \mathrm{~mm} / \mathrm{s}^{2}$, the unstable deformation occurs as shown in Figs.7(a) and (b). On the other hand, the unstable deformation was restrained under the condition of $a=2 \mathrm{~mm} / \mathrm{s}^{2}$. Therefore, it was found that the unstable deformation can be restrained with decreasing drawing speed acceleration. In addition, Fig. 8 shows the photographs of the deformation profiles of tubes under the condition of drawing speed acceleration $a$ of 2 and $20 \mathrm{~mm} / \mathrm{s}^{2}$ in the experiments. The unstable deformation can be more restrained for $a=2 \mathrm{~mm} / \mathrm{s}^{2}$ than for $a=20 \mathrm{~mm} / \mathrm{s}^{2}$. Furthermore, Fig. 9 shows the load - time curve under condition of $a=2$ and $20 \mathrm{~mm} / \mathrm{s}^{2}$. For $a=20 \mathrm{~mm} / \mathrm{s}^{2}$, the load is wobbly in the early drawing stage, while the load is stable in the case of $a=2 \mathrm{~mm} / \mathrm{s}^{2}$. Therefore, the advantage of restraining the unstable deformation by controlling the drawing speed was also confirmed experimentally.

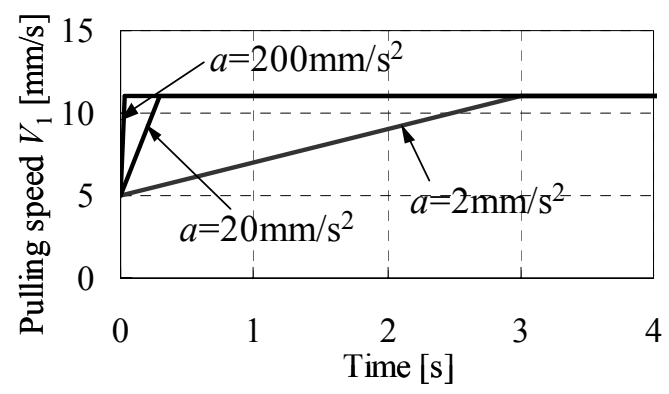

Fig. 6 Drawing speed control paths used in FE analysis

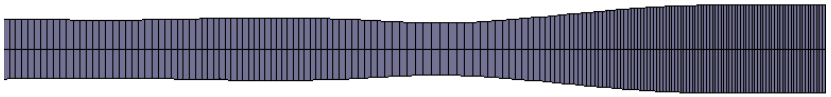

(a) $a=200 \mathrm{~mm} / \mathrm{s}^{2}$

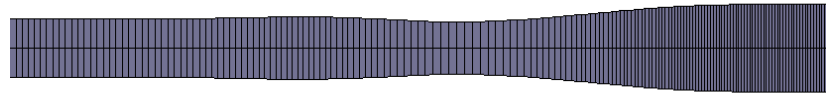

(b) $a=20 \mathrm{~mm} / \mathrm{s}^{2}$

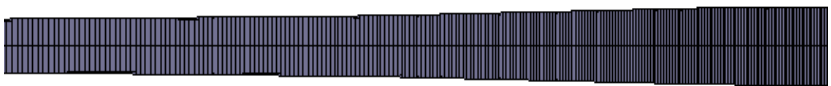

(c) $a=2 \mathrm{~mm} / \mathrm{s}^{2}$

$2 \mathrm{~mm}$

Fig. 7 Effect of drawing speed of acceleration on unstable deformation behavior obtained from $\mathrm{FE}$ analysis $\left(V_{2}=5 \mathrm{~mm} / \mathrm{s}, r=55 \%, T_{h}=1223 \mathrm{~K}\right)$

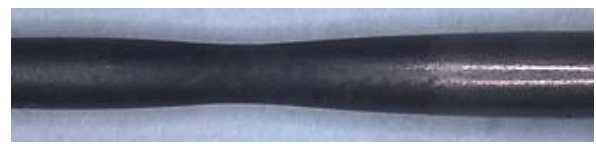

(a) $a=20 \mathrm{~mm} / \mathrm{s}^{2}$

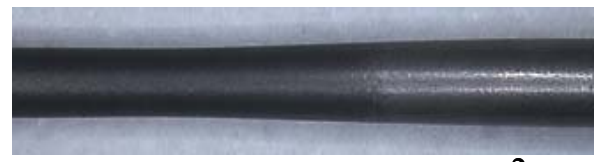

(a) $a=2 \mathrm{~mm} / \mathrm{s}^{2} \quad 2 \mathrm{~mm}$

Fig. 8 Effect of drawing speed of acceleration on unstable deformation behavior obtained from experiments $\left(V_{2}=5 \mathrm{~mm} / \mathrm{s}, r=33.3 \%, T_{h}=1223 \mathrm{~K}\right)$ 


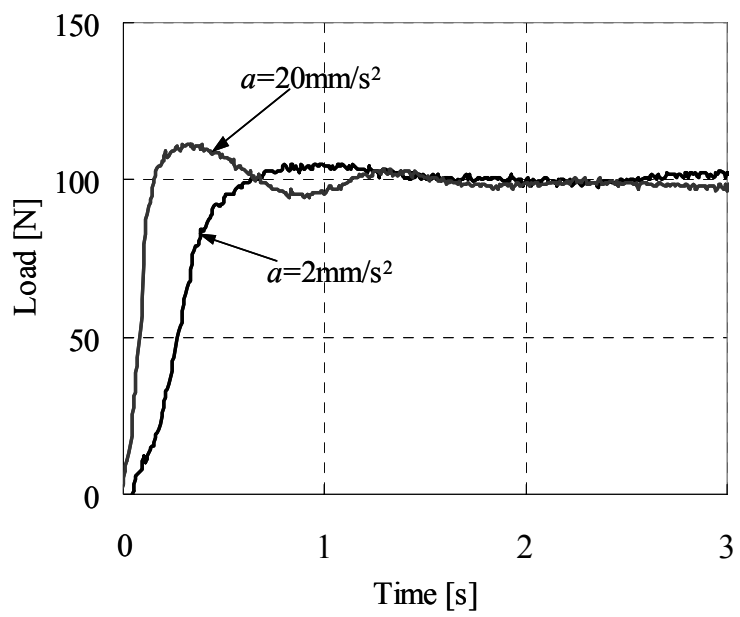

Fig. 9 Effect of drawing speed of acceleration on load-time curve $\left(V_{2}=5 \mathrm{~mm} / \mathrm{s}, r=33.3 \%, T_{h}=1223 \mathrm{~K}\right)$

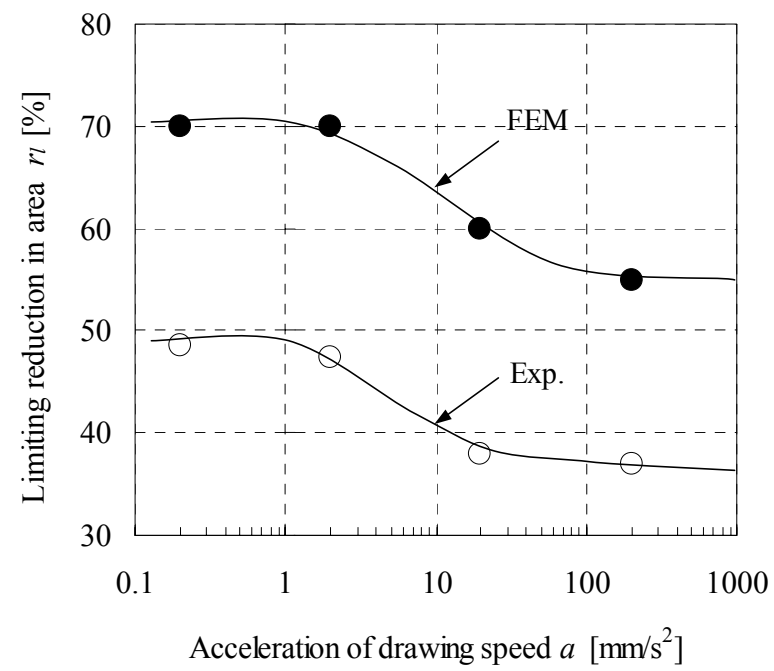

Fig. 10 Effect of acceleration of drawing speed on load-time curve $\left(V_{2}=5 \mathrm{~mm} / \mathrm{s}, T_{h}=1223 \mathrm{~K}\right)$

Figure 10 shows the effect of drawing speed of acceleration $a$ on the limiting reduction in area $r_{l}$ obtained from the experiment and FE analysis. There is a difference in the limiting reduction in area between the experiment and the FE analysis, because the limiting reduction in area $r_{l}$ obtained from FE analysis was estimated higher than the actual $r_{l}$ obtained from experiment. In the experiment, the improvement of limiting reduction in area $r_{l}$ cannot be confirmed in the case of the relatively high drawing speed of acceleration $a$. However, the limiting reduction in area $r_{l}$ is enhanced below $a=20 \mathrm{~mm} / \mathrm{s}^{2}$. Additionally, the limiting reduction in area $r_{l}$ does not change if the acceleration of drawing speed is too low in the FE simulation. Therefore, it is considered that this limiting reduction in area in the case of the acceleration of low drawing speed is actual forming limit of the workpiece. Consequently, the drawing speed control results in the $15 \%$ improvement in the limiting reduction in area $r_{l}$ determined from the experiment and FE analysis. Furthermore, if acceleration increases extremely, the deformation zone is also expanded. In this case, yielding percentage of the drawn tube is not so good. Therefore, there is a limit of acceleration as shown in Fig. 10. 


\section{Effective temperature distribution}

\subsection{Effect of temperature distribution}

To investigate the effect of temperature distribution on the fundamental deformation behavior, FE analysis was conducted under the heating length $h_{l}$ from 5 to $15 \mathrm{~mm}$, reduction in area $r=50 \%$, drawing speed acceleration $a=2 \mathrm{~mm} / \mathrm{s}^{2}$, and heating temperature $T_{h}=$ 1223K. Figure 11 shows the temperature distribution of the workpieces. It was confirmed that the temperature slope of longitudinal temperature distribution is gradual with increasing heating length $h_{l}$. Figure 12 shows the deformation profiles at the steady state deformation region. The tapering length of the tube at the deformed region was increasing with increasing the heating length $h_{l}$. The reason is that the deformation profile was determined from the distribution of the flow stress on the basis of the temperature distribution ${ }^{(8)}$.

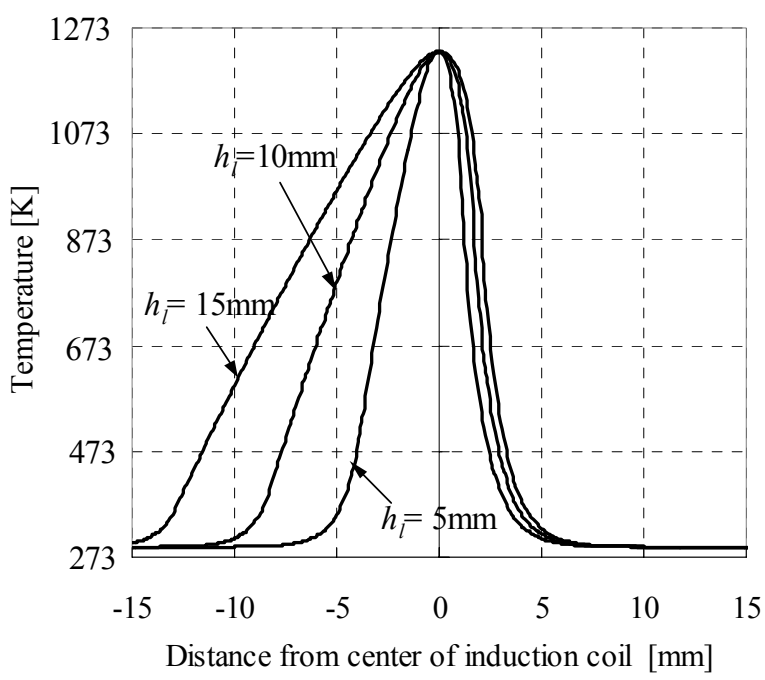

Fig. 11 Effect of heating length on temperature distribution in longitudinal direction on tube surface $\left(V_{2}=5 \mathrm{~mm} / \mathrm{s}, r=55.5 \%, T_{h}=1223 \mathrm{~K}\right)$

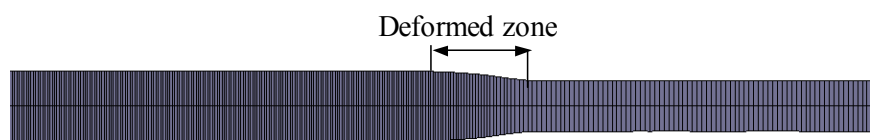

(a) $h_{\digamma}=5 \mathrm{~mm}$

Deformed zone

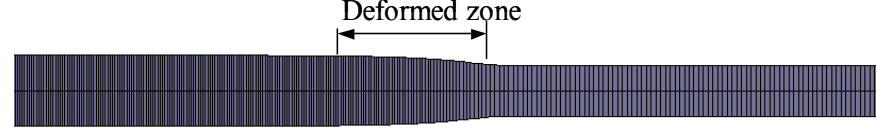

(b) $h_{\Gamma}=10 \mathrm{~mm}$

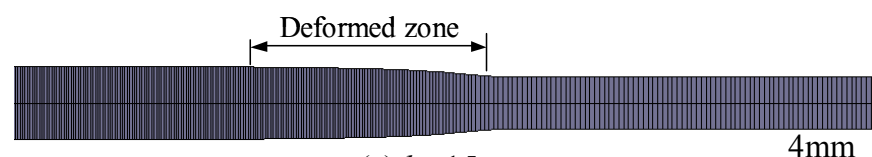

(c) $h_{l}=15 \mathrm{~mm}$

$4 \mathrm{~mm}$

Fig. 12 Effect of heating length on deformation profiles at steady state deformation region $\left(V_{2}=5 \mathrm{~mm} / \mathrm{s}\right.$, $\left.r=55.5 \%, T_{h}=1223 \mathrm{~K}\right)$

\subsection{Effect of heating length on dieless drawing limit}

The dieless drawing experiments were conducted under the heating coil length $h_{l}$ from 4 and $16 \mathrm{~mm}$, drawing speed acceleration $a=0.2$ and $2 \mathrm{~mm} / \mathrm{s}^{2}$ and heating temperature $T_{h}=$ $1223 \mathrm{~K}$ to investigate the effect of the heating length $h_{l}$ on the limiting reduction in area $r_{l}$ considering the drawing speed control as described above. Figure 13 shows the effect of 
heating coil length on the limiting reduction in area. In the case of drawing speed of acceleration $a=2 \mathrm{~mm} / \mathrm{s}^{2}$, the limiting reduction in area $r_{l}$ improves with decreasing heating coil length $h_{l}$. The enhancement of the forming limit by local heating has already been reported ${ }^{(3)}$. However, the previous reports did not differentiate between the forming limit caused by the unstable deformation and that caused by the difference in the flow stress of the materials between the heated and cooled parts. Thus, the effect of the temperature distribution on the forming limit was not investigated appropriately. On the other hand, in the experiment, the limiting reduction in area $r_{l}$ was obtained under a lower drawing speed of acceleration $a$ of $0.2 \mathrm{~mm} / \mathrm{s}^{2}$ to restrain the unstable deformation. As a result, the limiting reduction in area $r_{l}$ improved by $5.5 \%$ under the condition of long heating coil length $h_{l}$ of $16 \mathrm{~mm}$. This limiting reduction in area $r_{l}$ in the case of $h_{l}=16 \mathrm{~mm}$ is higher than that in the case of $h_{l}=4 \mathrm{~mm}$ by using the effective drawing speed control under $a=0.2 \mathrm{~mm} / \mathrm{s}^{2}$. Therefore, this indicates that the local heating in the dieless drawing is unnecessary.

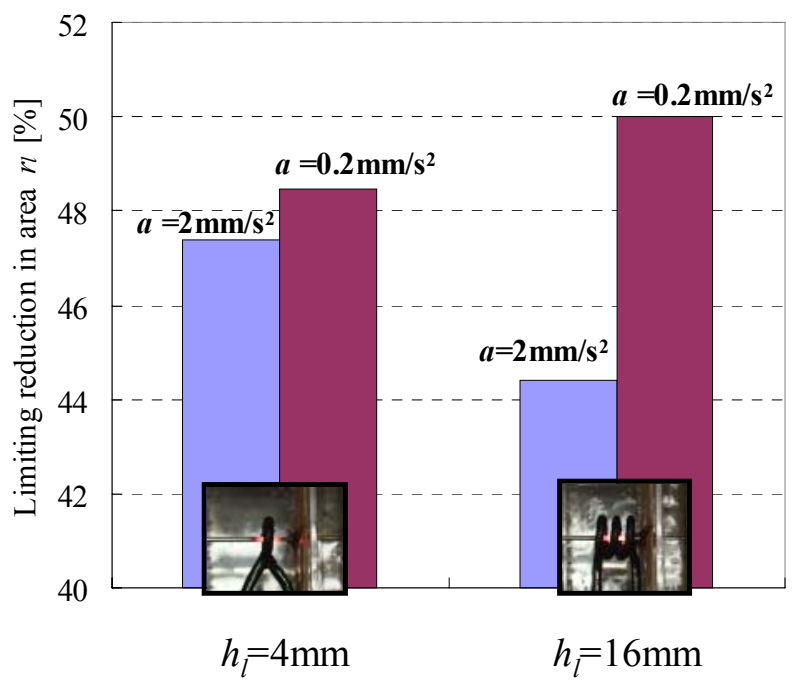

Fig. 13 Effect of heating length on limiting reduction in area $\left(V_{2}=5 \mathrm{~mm} / \mathrm{s}, T_{h}=1223 \mathrm{~K}\right)$

\section{Conclusions}

In this study, we suggested a new method for controlling the drawing speed to restrain the unstable deformation in dieless drawing. By this method, the effect of the acceleration of drawing speed and the temperature distribution on the limiting reduction in area, which means forming limit, was clarified. Additionally, the necessity of local heating during dieless drawing was also discussed.

The unstable deformation at the nonsteady state was restrained and the limiting reduction in area was improved by control the pulling speed in the early drawing stage.

In the case of normal dieless drawing without controlling the drawing speed, the local heating was necessary as reported in conventional studies. However, the local heating in the dieless drawing was unnecessary if the drawing speed is controlled.

\section{References}

(1) V. Weiss, R. A. Kot, Dieless Wire Drawing with Transformation Plasticity, Wire Journal, Vol. 9 (1969) 182-189

(2) J. M. Alexander, T. W. Turner, A Preliminary Investigation of the Die-less Drawing of Titanium and Some Steels, Proceedings of the Int. M. T. D. R. Conference: advance in machine tool design and research, 15 (1974) pp. 525-537 
(3) H. Sekiguchi, K. Kobatake, K. Osakada, A Fundamental Study on Dieless Drawing", Proceedings of the Int. M. T. D. R. Conference: advance in machine tool design and research, 15 (1974) pp. 539-544

(4) R. Carolan, P. Tiernan, P. Commerford, The Dieless Drawing of High Carbon Steel, Materials Science Forum, vol. 447-448 (2004) pp. 513-520

(5) K. Eynatten, J. N. Reissner, Dieless Drawing for Flexible Processing of Microstructure and Mechanical Properties, Proceedings of the 34th Int. MATADOR Conference: formerly the Int. Machine Tool Design and Research Conferences, 34 (2004) pp. 187-192

(6) T. Furushima and K. Manabe, Experimental study on multi-pass dieless drawing process of superplastic Zn-22\%Al alloy microtubes, Journal of Materials Processing Technology, Vol. 187-188 (2007) pp. 236-240

(7) T. Furushima and K. Manabe, Experimental and numerical study on deformation behavior in dieless drawing process of superplastic microtubes, Journal of Materials Processing Technology, Vol. 191 (2007) pp. 59-63

(8) M. Murahashi, Development of Continuous Dieless Drawing Process for Wire, Journal of the Japan Society for Technology of Plasticity, Vol. 31, No. 355 (1990) pp. 978-983 (in Japanease)

(9) T. Furushima, T. Sakai and K. Manabe, Finite Element Modeling of Dieless Tube Drawing of Strain Rate Sensitive Material with Coupled Thermo-Mechanical Analysis, Proceedings of the 8th International Conference on NUMIFORM (2004) 522-527.

(10) J. W. H. Price, J. M. Alexander, An Analytical Solution for Dieless Drawing Utilizing a Method of Equalisation of Work Rate, Proceedings of the Int. M. T. D. R. Conference: advance in machine tool design and research, 18(1977) pp. 259-265

(11) O. Pawelski, A. Kolling, Calculation of the Temperature Distribution in Dieless Drawing, steel research, Vol. 66(1995) pp. 50-54

(12) W. Wengenroth, O. Pawelski, W. Rasp, Theoretical and Experimental Investigations into Dieless Drawing, steel research, Vol. 72(2001) pp. 402-405

(13) Y. Li, N. R. Quick, A. Kar, Thermomechanical Effects in Laser Microprocessing for Dieless Metal Wire Drawing, Journal of Laser Application, Vol. 14, No. 2 (2002) pp. 91-99

(14) R. Fortunier, H. Sassoulas, F. Montheillet, A Thermo-mechanical Analysis of Stability in Dieless Wire Drawing, International Journal of Mechanical Sciences, Vol. 39, No. 5 (1997) pp. 615-627

(15) K. Kobatake, H. Sekiguchi, K. Osakada, K. Yoshikawa, An Analysis of Temperature Distribution in Continuous Dieless Drawing, Proceedings of the Int. M. T. D. R. Conference: advance in machine tool design and research, 18 (1977) pp. 253-258

(16) T. Furushima, K. Manabe, Finite Element Simulation with Coupled Thermo-mechanical Analysis of Superplastic Dieless Tube Drawing Considering Strain Rate Sensitivity, Journal of the Japan Society for Technology of Plasticity, Vol. 48, No. 552 (2007) pp. 51-55 (in Japanease)

(17) S. Hashizume, Resistance to Plastic Deformation of Metals (Stainless Steel), Journal of the Japan Society for Technology of Plasticity, Vol. 6, No. 49 (1965) pp. 71-75 (in Japanease) 